Rev. Int. Contam. Ambie. 35 (Calidad de agua: salud, remediación y perspectiva) 37-44, 2019

DOI: 10.20937/RICA.2019.35.esp03.05

\title{
EFECTO DEL COBRE PARA LA REMOCIÓN DE SULFATO EN UN REACTOR DE LECHO FIJO
}

Copper effect in sulfate removal using a fixed bed reactor

\author{
Cynthia Denisse LORETO MUÑOZ ${ }^{1}$, María Teresa CERTUCHA BARRAGÁN ${ }^{1}$, \\ Francisco Javier ALMENDARIZ TAPIA ${ }^{1}$, Valeria OCHOA-HERRERA ${ }^{2}$ y Onofre MONGE AMAYA ${ }^{1 *}$
}

${ }^{1}$ Unidad Centro, Laboratorio de Biorremediación, Departamento de Ingeniería Química y Metalurgia, Universidad de Sonora. Rosales y Blvd. Luis Encinas, Hermosillo, Sonora, México

${ }^{2}$ Colegio de Ciencias Ingenierías-Politécnico, Universidad San Francisco de Quito, Diego de Robles y Vía Interoceánica s/n, Quito, Ecuador

*Autor de correspondencia: onofre.monge@unison.mx

(Recibido febrero 2018, aceptado octubre 2018)

Palabras clave: cobre, sulfato reducción, reactor de lecho fijo

\section{RESUMEN}

La explotación de minerales ricos en pirita genera un drenaje ácido (DAM), el cual presenta un $\mathrm{pH}$ ácido, alta concentración de metales y sulfatos, y pueden causar problemas ambientales. En los últimos 20 años se han estudiado sistemas pasivos para el tratamiento de DAM, como las lagunas anaerobias, biorreactores y las barreras permeables. Los biorreactores, en condiciones controladas, emplean inóculos de bacterias sulfato reductoras (BSR) para tratar efluentes y precipitar metales de grado comercial. El objetivo de este trabajo fue analizar el efecto del cobre $(\mathrm{Cu})$ en la remoción de sulfato en un reactor de lecho fijo. Durante $28 \mathrm{~d}$ se operó un reactor de lecho fijo, con un tiempo de residencia hidráulico (TRH) de 12 h y $0.67 \mathrm{~g} \mathrm{DQO} / \mathrm{g}$ $\mathrm{SO}_{4}{ }^{2-}$. Durante $7 \mathrm{~d}$ la Fase I (solución sintética con $50 \mathrm{mg} \mathrm{Cu} / \mathrm{L}$ ) permitió una remoción de $\mathrm{Cu}$ del $99.59 \pm 0.43 \%$ y una producción de sulfuro de $39.29 \mathrm{mg} \mathrm{S}^{2-} / \mathrm{L} \cdot \mathrm{d}$. Posteriormente, el reactor operó sin $\mathrm{Cu}$ (Fase II), para demostrar que no se afectó la


alteraciones significativas en la remoción de materia orgánica y sulfato, así como en la producción de sulfuro después de la adición de $\mathrm{Cu}$. Se concluye que se pueden utilizar las BSR para el tratamiento de DAM.

Key words: copper, sulfate-reduction, fixed bed reactor

\begin{abstract}
Mining of sulfide-rich pyritic ores produce acid mine drainage (AMD), which contains high metal concentrations and have acid $\mathrm{pH}$, causing major environmental problems. Over the last 20 years a variety of passive AMD treatment systems, like anaerobic wetlands, bioreactors and permeable reactive barriers, have been studied. Under controlled conditions bioreactors employ inoculants of sulfate-reducing bacteria (SRB) to treat effluents and capture commercial grade metals. The objective of this research was to evaluate the effect of $\mathrm{Cu}$ on the removal efficiency of sulfate in a fixed bed reactor. During $28 \mathrm{~d}$ the fixed bed reactor maintained a hydraulic residence time (HRT) of
\end{abstract}


$12 \mathrm{~h}$ and an influent rate of $0.67 \mathrm{gCOD} / \mathrm{gSO}_{4}{ }^{2-}$. Phase I (synthetic solution with $50 \mathrm{mg}$ $\mathrm{Cu} / \mathrm{L}$ ) lasted $7 \mathrm{~d}$, allowing $\mathrm{Cu}$ removal of $99.59 \pm 0.43 \%$ and sulfide production of $39.29 \mathrm{mg} \mathrm{S}{ }^{2-} / \mathrm{L} \cdot \mathrm{d}$. Sulfate-reducing activity (SRA) was not affected $\left(40.25 \mathrm{mg} \mathrm{S}^{2-} / \mathrm{L} \cdot \mathrm{d}\right)$ during Phase II ( $21 \mathrm{~d}$ without $\mathrm{Cu}$ ). Results showed no significant alteration in sulfate and COD removal, as well as sulfur production after the addition of $\mathrm{Cu}$. It is concluded that $\mathrm{SRB}$ can be used for AMD treatment.

\section{INTRODUCCIÓN}

Los efluentes mineros varían su composición sólida y líquida en función del proceso, así como por el método de enriquecimiento y el tratamiento que recibe el mineral. Las aguas de mina se pueden clasificar en tres grupos: drenajes ácidos (DAM) con $\mathrm{pH}$ menor a 6; drenajes neutros con $\mathrm{pH}$ mayor a 6; drenajes alcalinos con $\mathrm{pH}$ mayor a 6 y con concentraciones de carbonatos mayores a $1000 \mathrm{mg} / \mathrm{L}$ (Iakovleva et al. 2015). Los DAM son resultado de la oxidación de sulfurados como la pirita, y la marcasita, así como de la lixiviación de metales provenientes de rocas sulfurosas cuando son expuestas al aire y al agua. $\mathrm{Su}$ característica principal es que tienen un $\mathrm{pH}$ ácido, así como concentraciones altas de metales y sulfatos (Vijayaraghavan y Yun 2008). Está bien documentado que la presencia de metales pesados en el agua puede ocasionar daños a la salud humana, incluso a bajas concentraciones (van den Brand et al. 2015). A nivel molecular pueden ocasionar bloqueo de grupos funcionales en biomoléculas, como la cisteína, desplazamiento de centros catiónicos en enzimas importantes y la formación de especies reactivas de oxígeno dañando carbohidratos, el ADN, proteínas y lípidos (Covarrubias y Peña Cabriales 2017). La ingesta de organismos de la cadena trófica con alta carga de elementos metálicos tóxicos ocasiona problemas en la salud humana, especialmente en infantes, dado que sus sistemas corporales aún están en desarrollo y que su ingesta es proporcionalmente mayor que la de un adulto (Lorenzo Márquez et al. 2016).

Las tecnologías de remediación para aguas contaminadas se pueden dividir en abióticas y bióticas (Schippers et al. 2013). Algunos ejemplos de tecnologías abióticas son la precipitación, remediación electroquímica, ósmosis inversa, ajuste de $\mathrm{pH}$, oxidación y la adsorción (Kalin et al. 2006). Las tecnologías de remediación abióticas existentes para la remoción de metales de aguas residuales pueden ser costosas o poco eficientes a bajas concentraciones del contaminante (Kiran et al. 2017).

Los tratamientos biológicos representan una alternativa eficiente y rentable, ya que permiten emplear tiempos de residencia hidráulica (TRH) cortos, volúmenes pequeños y son más económicos(van den Brand et al. 2015). Por ejemplo, los biorreactores anaerobios de flujo ascendente (UASB), de lecho fluidizado o de membrana, se han utilizado como una alternativa en la remediación de DAM, ya que son económicos y tecnológicamente viables ( $\mathrm{Lu}$ et al. 2016).

Una alternativa eficiente es la utilización de sulfuros, como producto de la actividad de las bacterias sulfato reductoras (BSR) para la precipitación de metales pesados (van den Brand et al. 2015). Los sulfuros reaccionan con los metales formando precipitados insolubles (Martins et al. 2009). No obstante, algunos parámetros que afectan la actividad sulfato reductora son la salinidad, la temperatura, el pH, el oxígeno, la concentración de sulfato (relación $\mathrm{DQO} / \mathrm{SO}_{4}{ }^{2-}$ ) y la composición de la materia orgánica (DQO) (van den Brand et al. 2015). Una limitación en la utilización de la reducción de sulfatos para la remediación de DAM es que la mayoría de las especies de BSR son sensibles a la acidez (Ivan y Johnson 2014). El pH óptimo para el crecimiento de BSR se encuentra en el rango de 5 a 9, pero existen bacterias resistentes a medio ácido (Elliott et al. 1998).

Los metales pesados son tóxicos para los microorganismos, incluidas las BSR, debido a que sustituyen los iones esenciales en sitios celulares, bloqueando los grupos funcionales de las enzimas. Sin embargo, existen algunos microorganismos que son metalotolerantes. Hay consorcios bacterianos resistentes a concentraciones letales de metales pesados, como Fe (400 mg/L), Zn (150 g/L) y Cu (80 mg/L) (Martins et al. 2009).

La carga orgánica volumétrica g DQO/g SO ${ }_{4}^{2-}$ en la alimentación puede ser utilizada para controlar la producción de $\mathrm{H}_{2} \mathrm{~S}$ en la precipitación de metales (Schippers et al. 2013). A una relación de $0.67 \mathrm{~g}$ $\mathrm{DQO} / \mathrm{g} \mathrm{SO}_{4}{ }^{2-}$, con un $\mathrm{pH}$ ácido y añadiendo etanol como fuente de electrones se alcanzó una reducción de sulfatos entre el 70 y el $92 \%$ y una precipitación de metales mayor al $99 \%$ (Sahinkaya y Yucesoy 2010). A una relación $\mathrm{DQO} / \mathrm{SO}_{4}{ }^{2-}$ estequiométrica 
de 0.67 , se alcanza alrededor del $60 \%$ de actividad sulfato reductora (Bratkova et al. 2013).

La precipitación de sulfuros metálicos depende del tamaño de partícula de los sulfuros formados, así como (TRH). Por ejemplo, en reactores de lecho fluidizado inverso (IFBR) operados a un TRH de 24 $\mathrm{h}$ y una relación de $1 \mathrm{~g} \mathrm{DQO} / \mathrm{g} \mathrm{SO}_{4}{ }^{2-}$ se alcanzaron valores de remoción de materia orgánica, sulfato y $\mathrm{Cu}$ de 39.5, 44.3 y $99 \%$, respectivamente (Villa Gómez et al. 2015). Es importante especificar que en ocasiones los TRH cortos evitan que las BSR neutralicen la acidez y el precipitado de metales (Singh et al. 2011).

El objetivo de este trabajo fue evaluar el efecto de una solución sintética de cobre en la remoción de sulfato en un reactor de lecho fijo. Este trabajo fue realizado para analizar el comportamiento de un consorcio microbiano ante una alta concentración de $\mathrm{Cu}$ y pH bajo.

\section{MATERIALES Y MÉTODOS}

\section{Caracterización del agua de mina}

Un efluente minero fue caracterizado con base en parámetros fisicos y químicos y concentración de metales. Los metales cuantificados fueron $\mathrm{Cu}, \mathrm{Fe}$ y Mn, mediante absorción atómica con una matriz de $\mathrm{HNO}_{3}$ al $2 \%$. La concentración de sulfatos se realizó según el método turbidimétrico, la demanda química de oxígeno (DQO), relación de sólidos suspendidos volátiles (SSV) y sólidos suspendidos totales (SST) según los métodos indicados en Standard Methods for the Examination of Water and Wastewater, edición 22 (Rice et al. 2012). Además, se determinó el pH con un potenciómetro Hanna Instruments pH 211.

\section{Análisis en el reactor de lecho fijo}

El sistema consistió de un reactor de lecho fijo construido con una columna de acrílico de $40 \mathrm{~cm}$ de alto y diámetro interno de $6.85 \mathrm{~cm}$, con un volumen de operación de 1.5 L (Fig. 1), y fue colocado en un cuarto de temperatura controlada a $35^{\circ} \mathrm{C}$. El reactor fue empacado con un soporte de zeolita clinoptilolita no activada con un tamaño de partícula de $2 \mathrm{~mm}$ y se inocularon $500 \mathrm{~mL}$ de biomasa anaerobia. Se utilizó zeolita clinoptilolita ya que es un buen soporte para inmovilizar biomasa, no pierde su estructura ni cambia sus propiedades. El inóculo presentó una relación de SSV/SST de $56.50 \%$ y $0.0928 \mathrm{~g} \mathrm{SSV/g}$ lodo. La velocidad de ascenso del flujo del reactor fue de $0.5426 \mathrm{~m} / \mathrm{h}$ y se mantuvo una recirculación de $48 \mathrm{~L} / \mathrm{d}$, para evitar la formación de canales preferenciales.

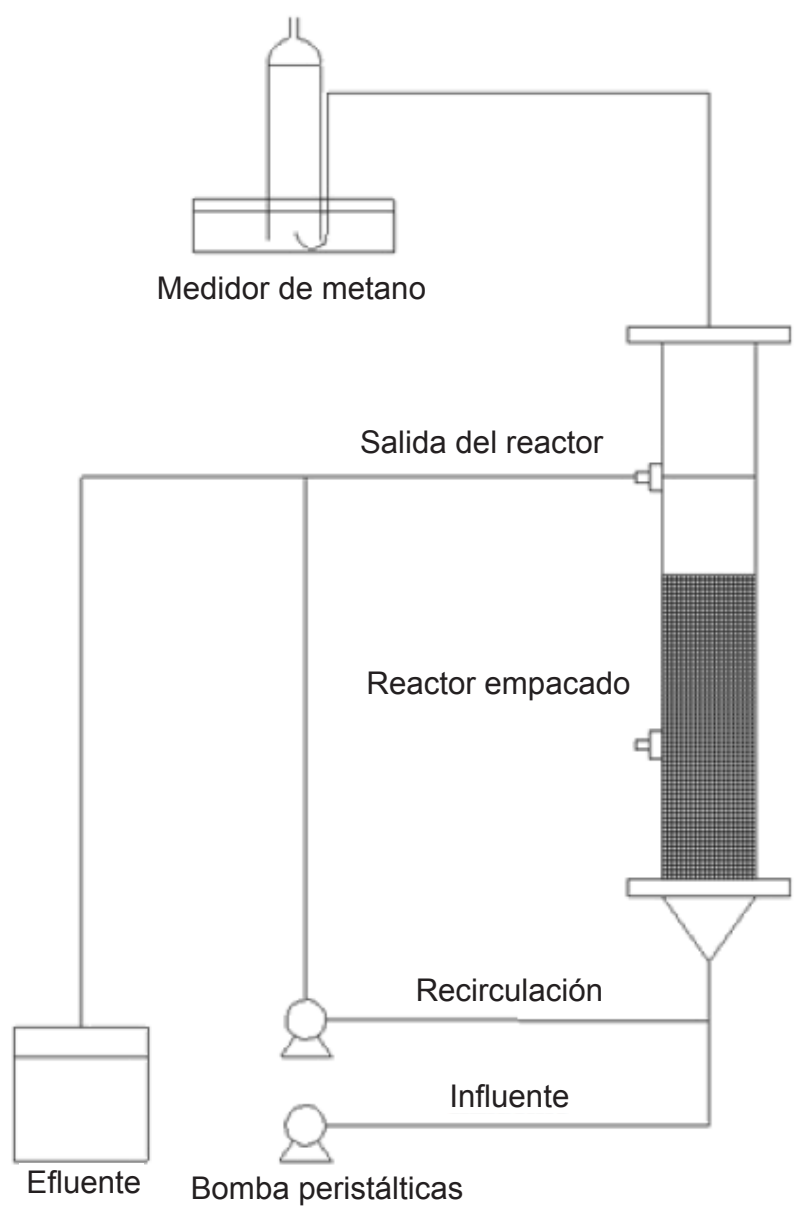

Fig. 1. Diagrama esquemático del reactor de lecho fijo utilizado en este estudio $\left(0.67 \mathrm{~g} \mathrm{DQO} / \mathrm{g} \mathrm{SO}_{4}{ }^{2-}, \mathrm{TRH}\right.$ de $12 \mathrm{~h}$ y $\left.37^{\circ} \mathrm{C}\right)$

Previo a la adición de $\mathrm{Cu}$, el reactor de lecho fijo operó con un TRH de $12 \mathrm{~h}, \mathrm{pH}$ de 7-8 y una relación de $0.67 \mathrm{~g} \mathrm{DQO} / \mathrm{g} \mathrm{SO}_{4}{ }^{2-}$, con sulfato de sodio $\left(\mathrm{Na}_{2} \mathrm{SO}_{4}\right)$ y glucosa $\left(\mathrm{C}_{6} \mathrm{H}_{12} \mathrm{O}_{6}\right)$ como fuente de carbono (Cuadro I).

$\mathrm{El}$ efecto del $\mathrm{Cu}$ en la remoción de sulfatos fue evaluado en dos fases. Durante la Fase I se alimentó una solución sintética, preparada con base en la caracterización del efluente de la mina con una concentración de $50 \mathrm{mg} \mathrm{Cu} / \mathrm{L}$, durante $7 \mathrm{~d}$. En la Fase II se alimentó un medio rico en sulfatos $\sin \mathrm{Cu}$, con el fin de estabilizar nuevamente el sistema. El cuadro II muestra la composición del medio y las condiciones de operación durante las dos fases.

Cada 24 h se determinó el pH, TRH, consumo de materia orgánica y sulfatos así como la producción de sulfuros, durante ambas fases. En la Fase I se monitoreó la remoción de $\mathrm{Cu}$ con un espectrómetro de absorción atómica marca Perkin Elmer modelo 
CUADRO I. COMPOSICIÓN DEL MEDIO BASAL MINERAL UTILIZADO

\begin{tabular}{|c|c|}
\hline Compuesto & $\mathrm{mg} / \mathrm{L}$ \\
\hline $\mathrm{NH}_{4} \mathrm{Cl}$ & 1045 \\
\hline $\mathrm{KCl}$ & 270 \\
\hline $\mathrm{KH}_{2} \mathrm{PO}_{4}$ & 170 \\
\hline $\mathrm{MgSO}_{4} \cdot 7 \mathrm{H}_{2} \mathrm{O}$ & 185 \\
\hline $\mathrm{CaCl}_{2} \cdot 2 \mathrm{H}_{2} \mathrm{O}$ & 50 \\
\hline $\mathrm{NaHCO}_{3}$ & 2000 \\
\hline Extracto de levadura & 20 \\
\hline Solución de elementos traza & $1 \mathrm{~mL} / \mathrm{L}$ \\
\hline
\end{tabular}

CUADRO II. CONCENTRACIONES PROMEDIO Y CONDICIONES DE OPERACIÓN DURANTE LA OPERACIÓN DEL RAFA

\begin{tabular}{lc}
\hline Parámetro & Valor promedio \\
\hline Sulfato $\left(\mathrm{g} \mathrm{SO}_{4}{ }^{2-} / \mathrm{L}\right)$ & 2.98 \\
DQO total $(\mathrm{g} / \mathrm{L})$ & 2 \\
$\mathrm{~g} \mathrm{DQO} / \mathrm{g} \mathrm{SO}_{4}{ }^{2-}$ & 0.67 \\
$\mathrm{Cu}(\mathrm{mg} / \mathrm{L})-$ sólo Fase I & 50 \\
$\mathrm{pH}$ & $5^{\mathrm{a}}-8^{\mathrm{b}}$ \\
TRH $(\mathrm{h})$ & 12 \\
Temperatura $\left({ }^{\circ} \mathrm{C}\right)$ & 37 \\
\hline
\end{tabular}

${ }^{\mathrm{a}}$ Fase I (días 1 - 7). ${ }^{\mathrm{b}}$ Fase 2 (días 8 a 21) con un rango de $\mathrm{pH}$ de 7 a 8.

AAnalyst 400. La producción de sulfuro se determinó siguiendo el procedimiento establecido en el método azul de metileno (Rice et al. 2012).

Además, se tomaron muestras del inóculo antes y después de la adición de $\mathrm{Cu}$ para analizar su estructura y composición mediante el equipo para microscopía electrónica de barrido (MEB) y dispersión de energía de rayos X (EDS, por sus siglas en inglés, modelo JM7800F con un Broker Detector X-Flash 6/60).

\section{RESULTADOS}

La caracterización fisica y química del efluente se muestra en el cuadro III. La muestra presentó un color entre café y amarillo, un precipitado característico de los óxidos de fierro $\left(\mathrm{Fe}_{2} \mathrm{O}_{3}\right)$ y un $\mathrm{pH}$ extremadamente ácido de 2.18. La concentración de $\mathrm{Cu}$ en el efluente sobrepasa la norma, la cual establece que el límite máximo permisible de descarga para $\mathrm{Cu}$ en aguas de uso agrícola es de $4 \mathrm{mg} / \mathrm{L}$ (NOM-001-SEMARNAT-1996). Por sus características, el efluente corresponde a un DAM, los cuales se identifican por tener un $\mathrm{pH}$ ácido (rango de 2.34 a 2.8), alta concentración de sulfatos $(2000-2500 \mathrm{mg} / \mathrm{L})$ y metales (Das et al. 2012, Xingyu et al. 2013).

CUADRO III. CARACTERIZACIÓN DEL EFLUENTE MINERO

\begin{tabular}{ccccccc}
\hline pH & $\begin{array}{c}\mathrm{SSV} / \mathrm{SST} \\
(\%)\end{array}$ & $\begin{array}{c}\mathrm{DQO} \\
(\mathrm{mg} / \mathrm{L})\end{array}$ & $\begin{array}{c}\mathrm{SO}_{4}^{2-} \\
(\mathrm{mg} / \mathrm{L})\end{array}$ & $\begin{array}{c}\mathrm{Cu} \\
(\mathrm{mg} / \mathrm{L})\end{array}$ & $\begin{array}{c}\mathrm{Fe} \\
(\mathrm{mg} / \mathrm{L})\end{array}$ & $\begin{array}{c}\mathrm{Mn} \\
(\mathrm{mg} / \mathrm{L})\end{array}$ \\
\hline 2.18 & 39.13 & 392.18 & 2467.86 & 59 & 1827.5 & 125
\end{tabular}

Durante la operación del reactor de lecho fijo el $\mathrm{pH}$ aumentó significativamente. En ambas fases el $\mathrm{pH}$ se neutralizó a valores entre 7 y 8, por efecto de los carbonatos producidos en el proceso de sulfato reducción.

En términos del consumo de materia orgánica, la adición de $\mathrm{Cu}$ no tuvo un efecto negativo (Fig. 2). El consumo de materia orgánica se mantuvo estable con eficiencias de $41.44 \pm 13.21 \%$ (Fase I) y 32.72 $\pm 14.08 \%$ (Fase II); sin embargo, fue menor al $50 \%$. El consumo de sulfato fue de $74.24 \pm 11.55 \%$ para la Fase I y $73.12 \pm 7.94 \%$ para la Fase II.

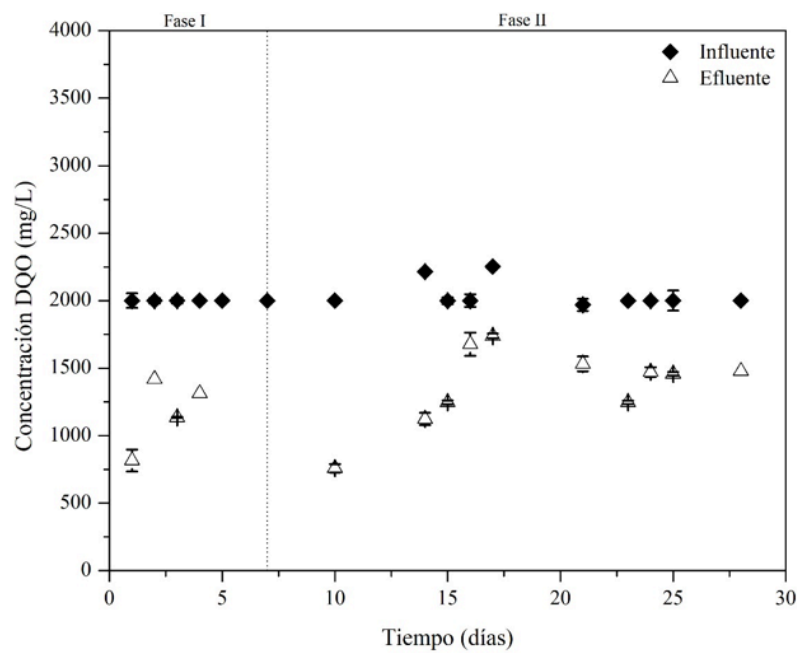

Fig. 2. Consumo de materia orgánica en presencia $(50 \mathrm{mg} \mathrm{Cu} / \mathrm{L})$ y ausencia de $\mathrm{Cu}$ durante la operación del reactor de lecho fijo $\left(0.67 \mathrm{~g} \mathrm{DQO} / \mathrm{g} \mathrm{SO}_{4}{ }^{2-}\right.$, TRH de $12 \mathrm{~h}$ y $\left.37^{\circ} \mathrm{C}\right)$

El comportamiento del reactor de lecho fijo en términos de consumo de sulfato y producción de sulfuros se puede observar en la figura 3. La 
producción de sulfuro no sufrió cambios significativos con la adición de $\mathrm{Cu}$, manteniendo valores de $1013.46 \pm 54.06 \mathrm{mg} \mathrm{S}^{2-} / \mathrm{L} \cdot \mathrm{d}$. (Fase I) y $1203.96 \pm$ $237.72 \mathrm{mg} \mathrm{S}^{2} / \mathrm{L} \cdot \mathrm{d}$. (Fase II). En la Fase I se alcanzó una remoción casi total de $\mathrm{Cu}(99.59 \pm 0.43 \%) \mathrm{du}-$ rante los $7 \mathrm{~d}$ en que se alimentó $\mathrm{Cu}$ al reactor, como se muestra en la figura 4.



Fig. 3. Comportamiento de las especies de azufre $\left(\mathrm{SO}_{4}{ }^{2-}\right.$ y $\left.\mathrm{S}^{2-}\right)$ en presencia $(50 \mathrm{mg} \mathrm{Cu} / \mathrm{L})$ y ausencia de $\mathrm{Cu}$ durante la operación del reactor de lecho fijo $\left(0.67 \mathrm{~g} \mathrm{DQO} / \mathrm{g} \mathrm{SO}_{4}{ }^{2-}\right.$, TRH de $12 \mathrm{~h}$ y $37^{\circ} \mathrm{C}$ ), donde I es el influente y E es el efluente del reactor anaerobio sulfato reductor (RASR)

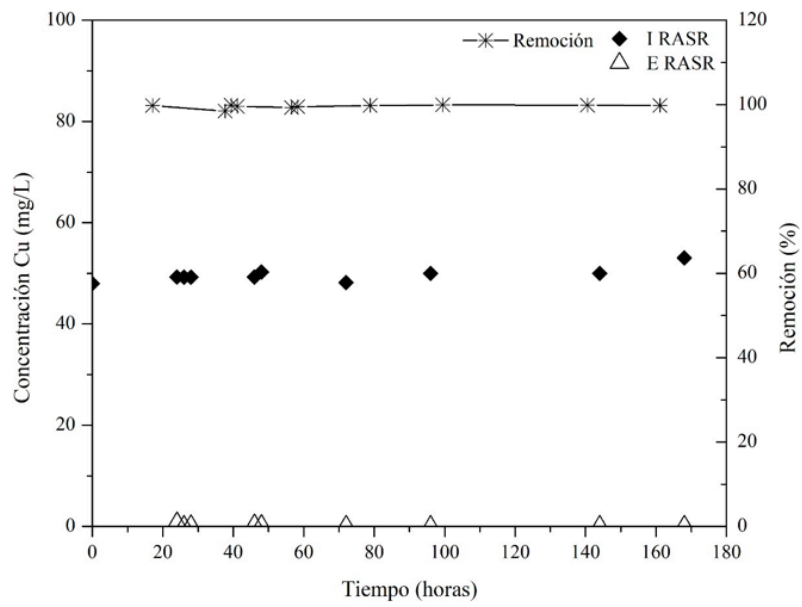

Fig. 4. Remoción de $\mathrm{Cu}$ durante la Fase I de operación del reactor de lecho fijo $\left(0.67 \mathrm{~g} \mathrm{DQO} / \mathrm{g} \mathrm{SO}_{4}{ }^{2-}\right.$, TRH de 12 h y $37^{\circ} \mathrm{C}$ ), donde I es el influente y E es el efluente del reactor anaerobio sulfato reductor (RASR)

Las figuras 5 y 6 muestran los análisis de microscopía electrónica de barrido del inóculo antes y después de la adición de $\mathrm{Cu}$. En la figura 5a se observan aglomeraciones de biomasa y algunos microorganismos bien definidos. Después de la adición de $\mathrm{Cu}$ (Fig. 6a) se observan cambios en la estructura de la biomasa y los microorganismos no se encuentran bien definidos. Con base en los resultados de EDS (Fig. 6b) se identifica la presencia de $\mathrm{Cu}$ y $\mathrm{S}$ sobre la biomasa, por el aumento en la intensidad de los picos después de la adición de $\mathrm{Cu}$.

\section{DISCUSIÓN}

El incremento del $\mathrm{pH}$ en el reactor puede deberse a que las BSR, al utilizar la glucosa, generaron $\mathrm{HCO}_{3}{ }^{-}$ , con lo que aumentó la alcalinidad. Esta reacción suele ocurrir a relaciones bajas de $\mathrm{DQO} / \mathrm{SO}_{4}{ }^{2-}$, de manera similar a lo reportado por Lu et al. (2016). El aumento en el $\mathrm{pH}$ promueve la sulfato reducción, lo cual favorece el rendimiento del reactor (Rodríguez et al. 2012). Los sustratos como la fructuosa, sacarosa y glucosa favorecen a las bacterias fermentativas, en vez de a las reductoras. Las bacterias acetogénicas compiten con las BSR por los productos intermedios de la fermentación, aun en condiciones de exceso de sulfato. Por esta razón los azúcares no son utilizados para procesos de sulfato reducción (Singh et al. 2011). El empleo de otra fuente de carbono podría favorecer el consumo de sulfato.

La adición de $\mathrm{Cu}$ no provocó un efecto significativo en la remoción de sulfato. Singh et al. (2011) demostraron que una concentración de $50 \mathrm{mg} \mathrm{Cr}(\mathrm{VI}) / \mathrm{L}$ no causaba alteraciones en un consorcio de BSR al utilizar lactato como fuente de carbono en un reactor anaerobio con un TRH de $3 \mathrm{~d}$. En estas condiciones se alcanzó una remoción de $\mathrm{Cr}(\mathrm{VI})$ del $96.7 \%$ y un consumo de sulfato del $90 \%$.

El Cu puede ser tóxico para las BSR, sin embargo el nivel de toxicidad varía según el tipo de microorganismo. Por ejemplo, para Desulfovibrio desulfuricans la concentración inhibitoria media $\left(\mathrm{CI}_{50}\right)$ es de $0.84 \mathrm{mg}$ $\mathrm{Cu} / \mathrm{L}$, mientras que para un consorcio es de $100 \mathrm{mg}$ $\mathrm{Cu} / \mathrm{L}$. La adición de sulfatos en digestores anaerobios previene la toxicidad de $\mathrm{Cu}$ debido a la formación de sulfuros, lo que indica que las BSR son tolerantes a concentraciones altas de $\mathrm{Cu}$ (Karri et al. 2006). La adición de $\mathrm{Cu}$ (Fase I) no alteró el consumo de materia orgánica y sulfatos ni la producción de sulfuros, con valores similares durante la Fase II, indicando que las bacterias toleraron la presencia del metal.

Las partículas de $\mathrm{CuS}$ en comparación con otros sulfuros metálicos, por ejemplo $\mathrm{ZnS}$, precipitan fácilmente. De acuerdo con Sahinkaya y Yucesor (2010) en reactores de lecho fluidizado la recuperación de sulfuros metálicos precipitados puede 


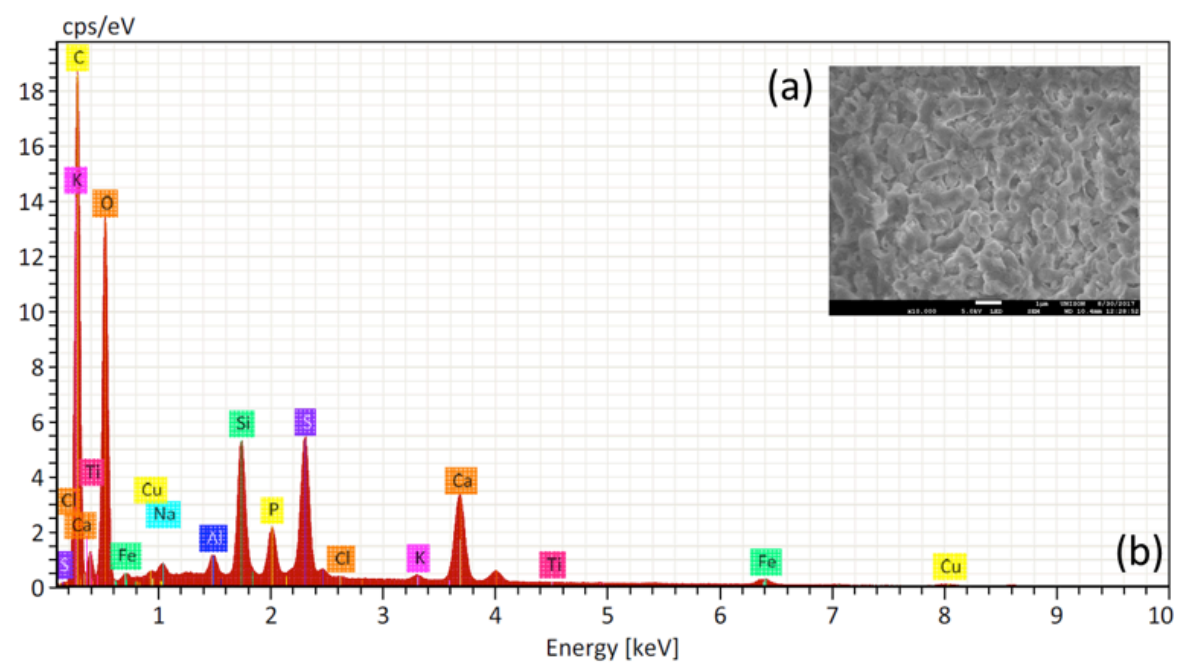

Fig. 5. (a) Fotomicrografía MEB, y (b) análisis EDS del inóculo antes de los estudios con $\mathrm{Cu}$

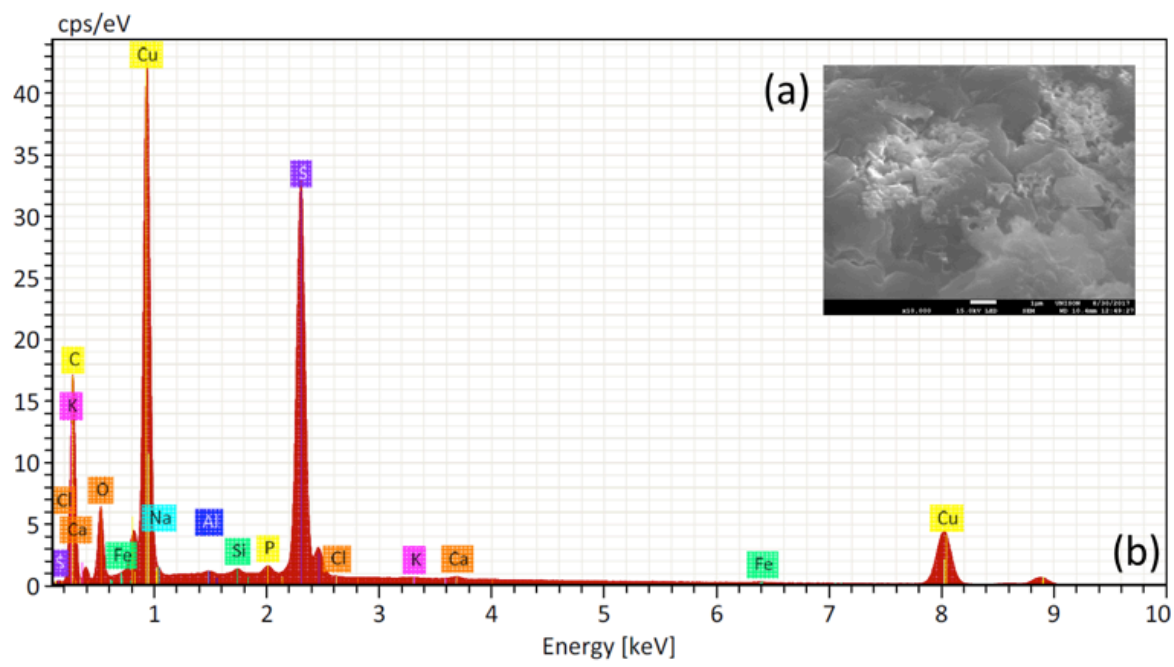

Fig. 6. (a) Fotomicrografía MEB, y (b) análisis EDS del inóculo después de la adición de Cu.

ocasionar pérdidas de BSR, lo que puede afectar su rendimiento; no obstante, en este estudio la adición de $\mathrm{Cu}$ no causó alteraciones en la operación del reactor de lecho fijo.

\section{CONCLUSIONES}

Se demostró que la adición de $\mathrm{Cu}$ no alteró el consumo de materia orgánica y sulfatos y que la producción de sulfuros se mantuvo constante. Los análisis de MEB de la biomasa mostraron cambios en la estructura de la biomasa después de estar en contacto con el metal. Esto se debe a que las BSR toleraron la presencia del metal durante los días de experimentación, sin embargo, el período de prueba fue corto. La toxicidad del $\mathrm{Cu}$ en la remoción de sulfatos debe ser estudiada con mayor detenimiento. El uso de BSR en un biorreactor de lecho fijo a un TRH bajo y en exceso de sulfato para la remoción de $\mathrm{Cu}$ es posible, por lo cual se puede utilizar este sistema para la remoción de metales, a concentraciones semejantes a las encontradas en los DAM y con grandes volúmenes de agua residual. 


\section{REFERENCIAS}

van den Brand, T. P. H., Roest, K., Chen, G. H., Brdjanovic, D., y van Loosdrecht, M. C. M. (2015). Potential for beneficial application of sulfate reducing bacteria in sulfate containing domestic wastewater treatment. World J. Microbiol. Biotechnol. 31(11):1675-1681. DOI: 10.1007/s11274-015-1935-X

Bratkova, S., Koumanova, B., y Beschkov, V. (2013). Biological treatment of mining wastewaters by fixedbed bioreactors at high organic loading. Bioresour. Technol. 137:409-413.

DOI: 10.1016/j.biortech.2013.03.177

Covarrubias, S. A., y Peña Cabriales, J. J. (2017). Contaminación ambiental por metales pesados en México: Problemática y estrategias de fitorremediación. Rev. Int. Contam. Ambient. 33:7-21. DOI: 10.20937/RICA.2017.33.esp01.01

Das, B. K., Mandal, S. M., y Bhattachasrya, J. (2012). Understanding of the biochemical events in a chemobioreactor during continuous acid mine drainage treatment. Environ. Earth Sci. 66(2):607-614.

DOI: $10.1007 / \mathrm{s} 12665-011-1268-5$

Elliott, P., Ragusa, S., y Catcheside, D. (1998). Growth of sulfate-reducing bacteria under acidic conditions in an upflow anaerobic bioreactor as a treatment system for acid mine drainage. Water Res. 32(12):3724-3730. DOI: 10.1016/S0043-1354(98)00144-4

Iakovleva, E., Mäkilä, E., Salonen, J., Sitarz, M., Wang, S., y Sillanpää, M. (2015). Acid mine drainage (AMD) treatment: Neutralization and toxic elements removal with unmodified and modified limestone. Ecol. Eng. 81:30-40. DOI: 10.1016/j.ecoleng.2015.04.046

Ivan, Ň., y Johnson, D. B. (2014). Removal of sulfate from extremely acidic mine waters using low $\mathrm{pH}$ sulfidogenic bioreactors. Hydrometallurgy 150:222-226. DOI: 10.1016/j.hydromet.2014.04.025

Kalin, M., Fyson, A., y Wheeler, W. N. (2006). The chemistry of conventional and alternative treatment systems for the neutralization of acid mine drainage. Sci. Total Environ. 366(2-3):395-408. DOI: 10.1016/j. scitotenv.2005.11.015

Karri, S., Sierra-Alvarez, R., y Field, J. A. (2006). Toxicity of copper to acetoclastic and hydrogenotrophic activities of methanogens and sulfate reducers in anaerobic sludge. Chemosphere 62(1):121-127.

DOI: 10.1016/j.chemosphere.2005.04.016

Kiran, M. G., Pakshirajan, K., y Das, G. (2017). Heavy metal removal from multicomponent system by sulfate reducing bacteria: Mechanism and cell surface characterization. J. Hazard. Mater. 324:62-70. DOI: 10.1061/(ASCE)EE.1943-7870.0001005.

Lorenzo Márquez, H., Torres Dosal, A., Barba Macías,
E., Ilizaliturri Hernández, C. A., Martínez-Salinas, R. I., Morales López, J. J., y Sánchez Moreno, I. (2016). Estimación de riesgo de exposición a metales pesados por consumo de plecos (Pterygoplichthys spp.) en infantes de comunidades ribereñas de los ríos Grijalva y Usumacinta, México. Rev. Int. Contam. Ambient. 32(2):153-164. DOI: 10.20937/RICA.2016.32.02.02

Lu, X., Zhen, G., Ni, J., Hojo, T., Kubota, K., y Li, Y. Y. (2016). Effect of influent COD/SO4 ratios on biodegradation behaviors of starch wastewater in an upflow anaerobic sludge blanket (UASB) reactor. Bioresour. Technol. 214:175-183.

DOI: 10.1016/j.biortech.2016.04.100

Martins, M., Faleiro, M. L., Barros, R. J., Veríssimo, A. R., Barreiros, M. A., y Costa, M. C. (2009). Characterization and activity studies of highly heavy metal resistant sulphate-reducing bacteria to be used in acid mine drainage decontamination. J. Hazard. Mater. 166(23):706-713. DOI: 10.1016/j.jhazmat.2008.11.088

NOM-001-SEMARNAT-1996. Límites máximos permisibles de contaminantes en las descargas de aguas residuales en aguas y bienes nacionales. México, D.F.

Rice, E., Baird, R., y Eaton, A. D. (2012). Standard Methods for the Examination of Water and Wastewater. American Public Health Association.

Rodriguez, R. P., Oliveira, G. H. D., Raimundi, I. M., y Zaiat, M. (2012). Assessment of a UASB reactor for the removal of sulfate from acid mine water. Int. Biodeterior. Biodegrad. 74:48-53.

DOI: 10.1016/j.ibiod.2012.07.012

Sahinkaya, E., y Yucesoy, Z. (2010). Biotreatment of acidic zinc- and copper-containing wastewater using ethanolfed sulfidogenic anaerobic baffled reactor. Bioprocess Biosyst. Eng., 33(8):989-997.

DOI: $10.1007 / \mathrm{s} 00449-010-0423-9$

Schippers, A., Hedrich, S., Vasters, J., Drobe, M., Sand, W., y Willscher, S. (2013). Geobiotechnology I: Metal-related Issues. Adv. Biochem. Eng. Biotechnol., Springer Berlin Heidelberg.

Singh, R., Kumar, A., Kirrolia, A., Kumar, R., Yadav, N., Bishnoi, N. R., y Lohchab, R. K. (2011). Removal of sulphate, $\mathrm{COD}$ and $\mathrm{Cr}(\mathrm{VI})$ in simulated and real wastewater by sulphate reducing bacteria enrichment in small bioreactor and FTIR study. Bioresour. Technol. 102(2):677-682. DOI: 10.1016/j.biortech.2010.08.041

Vijayaraghavan, K., y Yun, Y.-S. (2008). Bacterial biosorbents and biosorption. Biotechnol. Adv. 26(3):266-291. DOI: 10.1016/j.biotechadv.2008.02.002

Villa Gomez, D. K., Enright, A. M., Rini, E. L., Buttice, A., Kramer, H., y Lens, P. (2015). Effect of hydraulic retention time on metal precipitation in sulfate reducing inverse fluidized bed reactors. J. Chem. Technol. Biotechnol. 90(1):120-129. DOI: 10.1002/jctb.4296 
Xingyu, L., Zou, G., Wang, X., Zou, L., Wen, J., Ruan, R., y Wang, D. (2013). A novel low pH sulfidogenic bioreactor using activated sludge as carbon source to treat acid mine drainage (AMD) and recovery metal sulfides: Pilot scale study. Miner. Eng. 48:51-55.

DOI: 10.1016/j.mineng.2012.11.004 